\title{
Endosteal hyperostosis, Worth type
}

INSERM

\section{Source}

INSERM. (1999). Orphanet: an online rare disease and orphan drug data base. Endosteal hyperostosis, Worth type. ORPHA:2790

Worth type autosomal dominant osteosclerosis is a sclerozing bone disorder characterized by generalized skeletal densification, particularly of the cranial vault and tubular long bones, which is not associated to an increased risk of fracture. 